\title{
春季台湾海峡西南部南海暖流起源： 海水氧同位素示踪
}

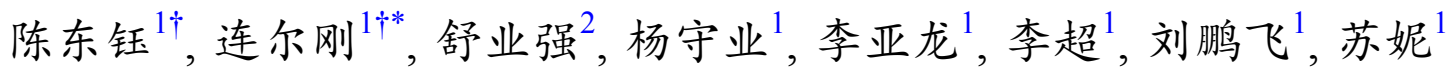

1. 同济大学海洋地质国家重点实验室, 上海 200092;

2. 热带海洋环境国家重点实验室, 中国科学院南海海洋研究所, 广州 510301

* 通讯作者, E-mail: eglian@tongji.edu.cn

$\dagger$ †共同第一作者

收稿日期：2019-12-06; 收修改稿日期：2020-03-29; 接受日期：2020-06-05; 网络版发表日期：2020-08-13

国家自然科学基金项目(批准号: 41706049、41730531和41776062)、中国博士后科学基金项目(编号：2018M642071)、“全球变化与海气相互 作用”专项项目(编号: GASI-GEOGE-03)和国家自然科学基金共享航次计划项目(批准号: 41749001)资助

摘要 海水氧同位素 $\left(\delta^{18} \mathrm{O}\right)$ 是示踪水团起源和混合过程的重要指标。文章依据台湾海峡西南部水文观测、HY$\mathrm{COM}$ 分析资料及海水氧同位素数据，探讨了台湾海峡西南部南海暖流的水体来源及其成因机制. 结果表明，黑潮 次表层水能够入侵至台湾海峡西南部陆坡区, 并在陆坡处伴有爬坡涌升现象. $\delta^{18} \mathrm{O}$-盐度关系进一步表明, 春季台 湾海峡西南部南海暖流起源于黑潮次表层水入侵南海形成的陆坡流爬坡偏转, 而非来源于海南岛东侧形成的南 海暖流西段。此外，浙闽沿岸流朝南延伸影响可至台湾浅滩处，并在台湾浅滩西侧约 $23.5^{\circ} \mathrm{N}$ 处离岸输送对南海暖 流产生一定的影响. 本研究也进一步揭示, 海水氧同位素相比传统温盐点聚图和HYCOM分析资料对水团的运动 和起源判别更敏感, 它们结合可以更可靠地示踪陆架水团混合过程.

关键词氧同位素, 南海暖流, 浙闽沿岸流, 黑潮, 台湾海峡西南部

\section{1 引言}

台湾海峡西南部北承东海与南海 $(\mathrm{SCS})$ 的重要通 道台湾海峡，南接南海海盆，东临吕宋海峡和西太平 洋, 发育广阔的陆架和陡峭的陆坡(图1a), 是中国重要 的渔场之一. 受地形、季风、黑潮入侵等因子的影响, 台湾海峡西南部环流结构多变, 各海流之间的相互作 用关系复杂 $(\mathrm{Hu}$ 等，2010；Liu等，2008；Shu等，2019， 2018, 2016; Su, 2004; 管秉贤, 1998; 舒业强等, 2018).
台湾海峡西南部的主要流系包括: 南海暖流(SCSWC, 又称“南海北部冬季逆风流”)、黑潮南海分支(SCSBK, 又称南海北部陆坡流)以及沿岸流( $\mathrm{Hu}$ 等, 2010; Liu等, 2008). 其中，南海暖流因其冬季逆风性及其在南海与 东海之间的物质交换中的重要作用而备受关注(Guan 和Fang, 2006).

南海暖流, 位于南海北部沿岸流的外侧, 大致沿着 100 200m等深线终年朝东北方向流动，流幅宽约 $160 \sim 300 \mathrm{~km}$; 以 $116^{\circ} \mathrm{E}$ 为界可分为东西两段, 东段流速

中文引用格式: 陈东钰, 连尔刚, 舒业强, 杨守业, 李亚龙, 李超, 刘鹏飞, 苏妮. 2020. 春季台湾海峡西南部南海暖流起源: 海水氧同位素示踪. 中国科学: 地球科 学, 50(10): 1492-1504, doi: 10.1360/SSTe-2019-0284

英文引用格式: Chen D, Lian E, Shu Y, Yang S, Li Y, Li C, Liu P, Su N. 2020. Origin of the springtime South China Sea Warm Current in the southwestern Taiwan Strait: Evidence from seawater oxygen isotope. Science China Earth Sciences, 63(10): 1564-1576, https://doi.org/10.1007/s11430-019-9642-8 


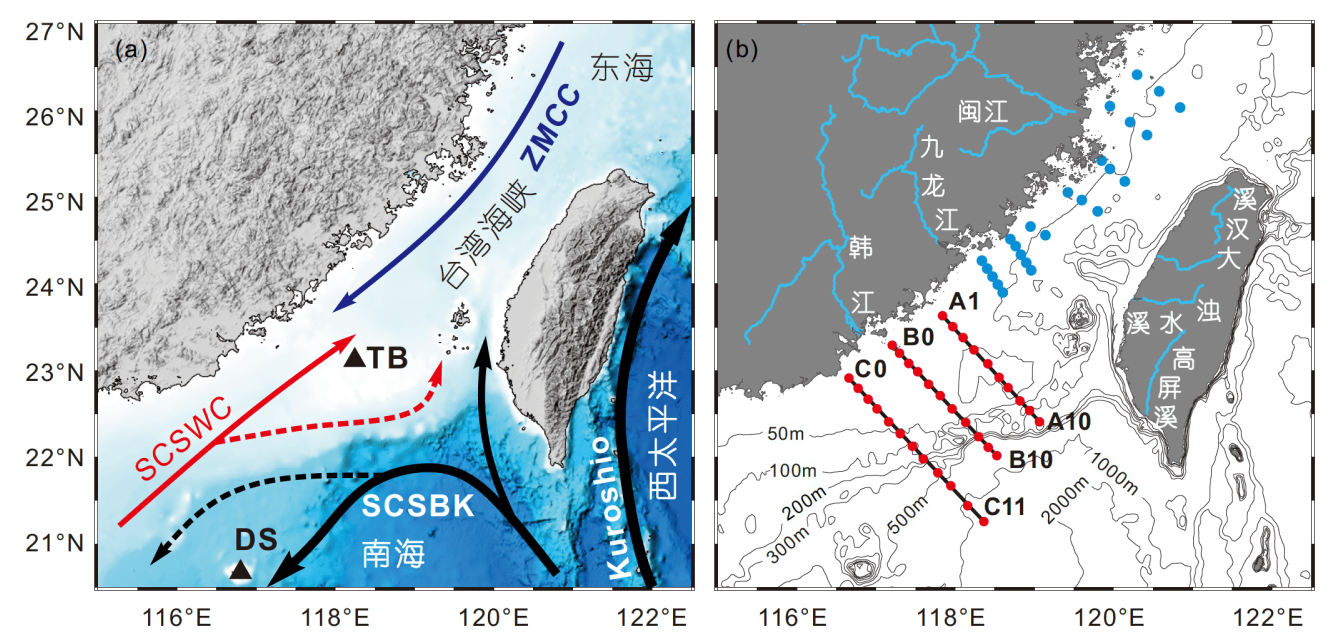

图 1 春季台湾海峡南部环流示意图(a)和样品站位分布图(b)

(a) SCSBK, 黑潮南海分支; SCSWC, 南海暖流; ZMCC, 浙闽沿岸流; Kuroshio, 黑潮; DS, 东沙岛; TB, 台湾浅滩. 修改自Hu等(2010). (b) 50 、 100、200、300、500、1000及2000m等深线以灰色线条表示，台湾海峡西部样品采自2018-03-24至03-28期间(蓝色圆点)，台湾海峡西南部样 品采自2018-04-10至04-14期间(红色圆点)

强 $\left(\sim 50 \mathrm{~cm} \mathrm{~s}^{-1}\right)$, 终年较稳定; 西段流速弱 $\left(\sim 20 \mathrm{~cm} \mathrm{~s}^{-1}\right)$, 流幅和流向不稳定(Wang等, 2011; Xie等, 2015; 管秉 贤，1978，1998). 南海暖流是在1959 1960年全国海洋 综合调查期间发现于粤东沿岸深水海区, 由管秉贤和 陈上及(1964)提出并命名. 嗣后, 多年的水文流场观测 进一步证实了南海暖流的存在(Guan, 1986; 管秉贤, 1978, 1985; 郭忠信等, 1985). 最早的正压数值模式结 果表明, 南海暖流主要受黑潮南海分支的影响, 其来源 包括黑潮延伸所反馈的海流、黑潮南海分支在陆坡区 向岸爬升偏转部分以及南海东北部反气旋涡的北翼 (Ma，1987). 随后, 诸多水文流场观测以及数值模拟就 南海暖流的成因机制开展了系统研究，其存在已经达 成共识, 然而关于南海暖流的成因机制至今尚存争议 (Guan和Fang, 2006; 舒业强等, 2018).

南海暖流的主要动力因子包括冬季风松弛、地 形、黑潮入侵、海表压强梯度力等因素(Guan和Fang, 2006; Liu等, 2008; 管秉贤, 1998), 其产生机制主要包 括以下观点: (1) 冬季风条件下形成的海南岛东侧水体 堆积, 由此产生的沿陆架方向的海表高度差, 是南海暖 流的诱因(Li等, 1993; 曾庆存等, 1989), 冬季风松弛导 致了南海暖流的出现(Chao等, 1995; Chiang等, 2008; Xie等, 2015); (2) 黑潮入侵引起的沿陆架方向压强梯 度力所致(Hsueh和Zhong, 2004), 而黑潮入侵在陆坡区 引起的跨陆架压强梯度力维持了南海暖流(Xue等,
2004); (3) 由台湾海峡北向输送诱导的“源-汇”流, 其能 量来源于南海暖流下游(Yang等, 2008); (4) 地形和斜 压联合效应(JEBAR) 导致陆坡流在陆坡区发生爬坡偏 转形成南海暖流(Wang等, 2010; 宏波和王东晓, 2006). 近来, 长时间序列的水文观测资料表明, 南海北部并不 存在持续的南海暖流(Li等, 2014; Tai等, 2017; Yang, 2006); 高分辨率的数值模式结果认为南海暖流东段是 黑潮入侵的结果, 而西段则与风场的Ekman抽吸形成 的高水位带有关(Wang等, 2011; Zhang等, 2018); 此 外, Xie等(2015)认为南海暖流的连续性与稳定性还与 南海东北部活跃的浴旋有关.

南海暖流的发现迄今已有 50 余年, 其来源及成因 机制仍然是南海北部环流研究的热点问题之一. 近年 来对南海暖流的起源及其成因机制研究多采用数值模 式方法, 然而由于模式在分辨率、强迫场、边界条件 的选取、参数化等存在一定不确定性, 导致了数值模 式输出结果迥异(Chao等, 1995; Chiang等, 2008; Hsueh和Zhong, 2004; Ma，1987; Xue等, 2004; Yang 等, 2008; Zhang等, 2018; 曾庆存等, 1989; 宏波和王东 晓, 2006). 尽管数值模式无论在气候态强迫场( $\mathrm{Li}$ 等, 1993; 曾庆存等, 1989)还是在天气尺度强迫场(Chiang 等, 2008)的驱动下, 以及无论是正压模式还是斜压模 式中(管秉贤, 1998), 都能模拟出南海暖流, 但它们对 其动力机制的解释却不尽相同; 此外, 近期的水文观测 
也否定南海暖流的持续存在( $\mathrm{Li}$ 等, 2014).

海水氧同位素组成作为区分不同水团物理特性的 有效示踪指标(Craig和Gordon, 1965; Fairbanks, 1982), 已被广泛应用于水团来源、运动路径及其混合过程示 踪(Bauch等，2005; Benetti等，2017; Benway和Mix, 2004; Conroy等, 2014; Lian等, 2016). 不同来源的海 水通常具有不同的氧同位素组成，且海水的氧同位素 具有保守性，几乎不受生物过程的影响，因此不同起 源的水团相互混合过程具有不同的 $\delta^{18} \mathrm{O}$-盐度关系 (Bauch等, 2005; Benetti等, 2017; Craig和Gordon, 1965; Fairbanks, 1982; Lian等, 2016). 因此本研究于2018年3 月和4月期间, 分别采集了台湾海峡西北部、西南部的 海水样品(图1b), 测定海水的 $\delta^{18} \mathrm{O}$, 并结合文献报道的 氧同位素数据及HYCOM分析资料，从水体来源的角 度入手，探讨春季台湾海峡西南部南海暖流的起源及 其成因机制.

\section{2 材料与方法}

\section{1 样品采集}

海水样品于2018年3 4月，分别采自台湾海峡西北 部和台湾海峡西南部(图1). 其中台湾海峡内部布设了 22 个站位，采样时间为2018年3月24日至3月27日，期间 盛行东北风(图2), 风速在4 $6 \mathrm{~m} \mathrm{~s}^{-1}$. 台湾海峡西南部布 设了 $\mathrm{A} 、 \mathrm{~B} 、 \mathrm{C}$ 三个断面，共计 33 个站位; 采样时间为 2018年4月10日至4月13日，期间正值东北风松弛，以南
风为主 $\left(2 \sim 5 \mathrm{~m} \mathrm{~s}^{-1}\right)$, 采样前经历强东北风天气 $\left(>10 \mathrm{~m} \mathrm{~s}^{-1}\right)$. 利用美国SeaBird公司出产的SBE 911 plus CTD进行 温、盐、深的水文观测, 由CTD-Rosette采水器采集各 站位不同深度海水样品, 至甲板后马上转入 $30 \mathrm{~mL}$ 聚乙 烯塑料瓶中, 装满密封并冷藏保存, 带回陆地实验室进 行海水 $\delta^{18} \mathrm{O}$ 的分析.

\section{2 氧同位素数据}

海水 $\delta^{18} \mathrm{O}$ 分析在同济大学海洋地质国家重点实验 室完成，采用液态水同位素分析仪(TIWA-45EP，美国 Los Gatos Research公司生产)测试海水 $\delta^{18} \mathrm{O}$. 其运用离 轴积分腔输出光谱技术, 对汽化水分子吸收光谱强度 及波长进行实时测量, 可直接测试水样的 ${ }^{18} \mathrm{O} /{ }^{16} \mathrm{O}$ 比率. 将冷藏的水样取出, 待升至室温, 经 $0.22 \mu \mathrm{m}$ 醋酸纤维滤 膜过滤后注入微量瓶中, 随后上机测试. 采用LGR公司 提供的据V-SMOW(维也纳标准平均海水)配置的二级 工作标样(LGR3C、LGR4C、LGR5C). 按照“LGR3C3 个样品-LGR 4C-3 个样品-LGR5C-3 个样品”序列进行 测试, 每个样品进行 8 次重复分析, 剔除前3次避免记忆 效应, 后5次取平均值. 测试精度: $\delta^{18} \mathrm{O}$ 优于 $0.1 \%$. 所有 测试结果用相对于V-SMOW的千分差 $\delta^{18} \mathrm{O}$ 来表示:

$\delta^{18} \mathrm{O}_{\text {sample }}=\left(\frac{R_{\text {sample }}}{R_{\mathrm{V}-\mathrm{SMOW}}}-1\right) \times 1000 \%$,

式中, $R_{\text {sample }}$ 和 $R_{\mathrm{V}-\mathrm{SMOW}}$ 分别是水样和维也纳标准平均 海水(V-SMOW)中的 ${ }^{18} \mathrm{O} /{ }^{16} \mathrm{O}$ 比率.
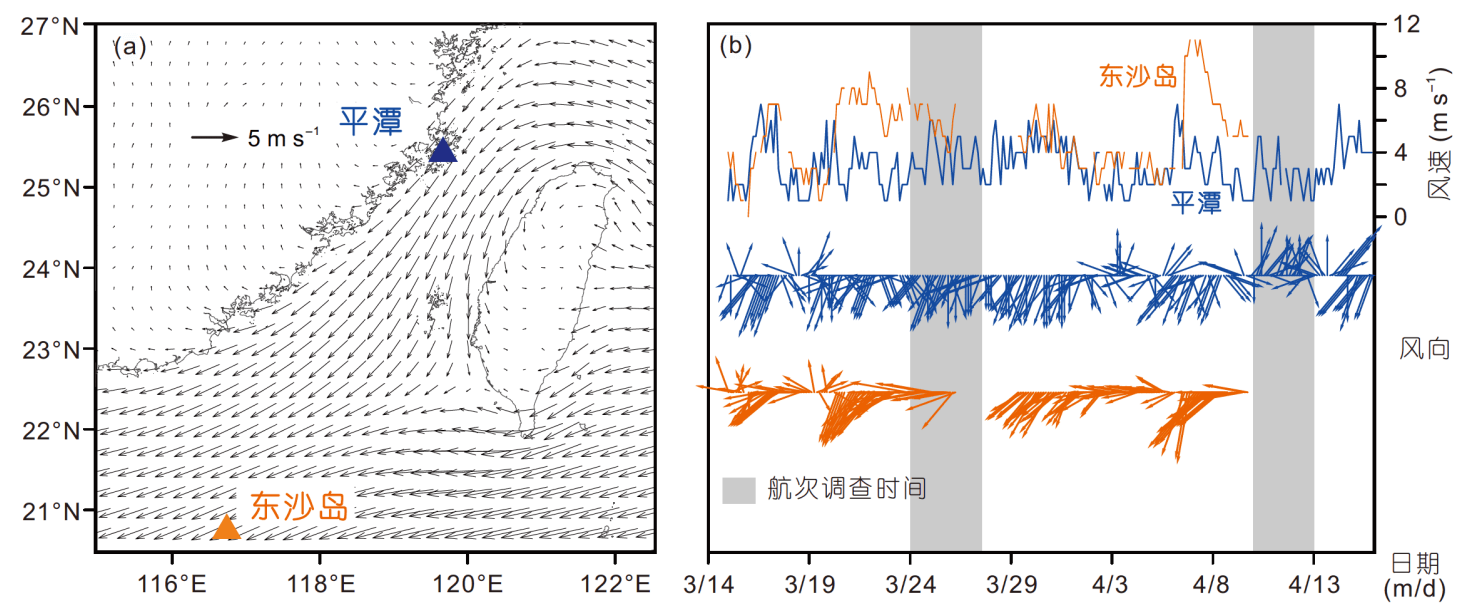

图 22018 年4月台湾海峡西南部 $10 \mathrm{~m}$ 经向和纬向组合ERA5再分析平均风场示意图(a)和2018年3月15日至4月15日平潭、东 沙岛3小时分辨率风速风向示意图(b)

(a) 数据来源: https://www.ecmwf.int/en/forecasts/datasets/reanalysis-datasets/era5; (b) 数据来源: http://ncdc.noaa.gov/isd 
典型黑潮水端元的 $\delta^{18} \mathrm{O}$ 数据引用自Horibe和 Ogura(1968), 通过公式 $\delta^{18} \mathrm{O}=\delta D / 7.5$ (Ferronskii和Poliakov, 1982)计算得出; 典型南海海水、吕宋海峡海水及 黑潮水 $\delta^{18} \mathrm{O}$ 数据引用自 $\operatorname{Lin}(2000)$ 和Chang (2000). 本文 海水温度、盐度及氧同位素数据见网络版附表 $\mathrm{S} 1$ (http://earthcn.scichina.com).

\subsection{HYCOM流场及温度数据}

HYCOM(hybrid coordinate ocean model)分析数据 同化了卫星高度计、多通道海表温度数据、抛弃式深 水温度计(expendable bathythermographs, XBTs)、温盐 深仪(conductivity temperature depth, CTD)和Argo浮标 等多种观测资料(Wallcraft和Metzger, 2009). 本文使用 的HYCOM分析数据包括了逐日的海洋温度和流场 (https://www.hycom.org/dataserver/gofs-3pt1/analysis), 该数据空间分辨率为 $1 / 12^{\circ} \times 1 / 12^{\circ}$.

\section{3 结果}

\section{1 表、底层温度、盐度及氧同位素分布}

研究区表层海水 $\delta^{18} \mathrm{O}$ 的变化范围为 $-0.71 \sim 0.58 \%$, 平均值 $0.10 \%$. 台湾海峡西北部表层海水温度 $(T)$ 、盐 度 $(S)$ 较低 $\left(T<22.5^{\circ} \mathrm{C}, S<33.5\right), \delta^{18} \mathrm{O}<0.20 \%$. $\delta^{18} \mathrm{O}$ 与盐 度分布基本一致，总体呈现由近岸向海峡中部逐渐升 高的趋势(图3), 最低值出现在九龙江口附近, $\delta^{18} \mathrm{O}=$ $-0.71 \%$. 表层低温低盐的海水主要分布在台湾海峡西 侧, 水深 $50 \mathrm{~m}$ 以西, 并自北向南延伸至九龙江口附近. 在台湾海峡中部地区，表层海水盐度和 $\delta^{18} \mathrm{O}$ 迅速增高 $\left(S>33.5, \quad \delta^{18} \mathrm{O}>0.20 \%\right)$. 台湾海峡南部表层海水的温 度、盐度较西部高 $\left(T>22.5^{\circ} \mathrm{C}, S>33.5\right)$, 其中, 在A、 B、C三个断面30 50m等深线之间存在一高盐高温的 水体, $\delta^{18} \mathrm{O}$ 值在 $\mathrm{B} 4 、 \mathrm{~B} 5$ 站位出现一个偏正的核心 $\left(\delta^{18} \mathrm{O}>0.40 \%\right)$, 同时, $\delta^{18} \mathrm{O}<0.20 \%$ 的水体呈舌状由南 向北贯穿于三个断面.

底层海水 $\delta^{18} \mathrm{O}$ 的变化范围为 $-0.60 \sim 0.58 \%$, 平均 $0.20 \%$. 台湾海峡西侧底层海水温度、盐度与表层分布 基本一致, 由近岸向海峡中部逐渐升高(图3), 底层海水 $\delta^{18} \mathrm{O}$ 多小于 $0.30 \%$, 海峡中部出现高值核心 $\left(\delta^{18} \mathrm{O}>0.30 \%\right)$. 台湾海峡南部陆架区域底层海水温度与 表层相似，高盐、高温的水体呈带状贯穿于A、B、C 三个断面，近岸B0、B1站位的底层海水温度、盐度相
对较低 $\left(S<34.3, T<21^{\circ} \mathrm{C}\right)$. 南部陆架区底层海水 $\delta^{18} \mathrm{O}$ 差 异较大，在B4、B5、C7站位观察到 $\delta^{18} \mathrm{O}>0.50 \% ; \mathrm{C} 2$ 、 $\mathrm{A} 5$ 和 $\mathrm{A} 6$ 站位存在低值, $\delta^{18} \mathrm{O}<0.30 \%$. 陆坡及向海延伸 区域底层水体温度较低, 盐度高于 $34.5, \delta^{18} \mathrm{O}<0.30 \%$ 。

\section{2 典型断面的温度、盐度及氧同位素分布}

$\mathrm{A}$ 断面总体水深较浅(小于 $150 \mathrm{~m}$, 图4), 海水 $\delta^{18} \mathrm{O}$ 变 化范围为 $0 \sim 0.40 \%$, 平均 $0.20 \%$. A 断面自西向东, 温度 和盐度的变化较小, 仅在 $\mathrm{A} 10$ 站位底层观察到高盐 $(S>34.6)$ 、低温 $\left(T<22^{\circ} \mathrm{C}\right)$ 的水体, $\delta^{18} \mathrm{O}$ 则呈现逐渐增大 到减小再增大的趋势. 其中, A1站位的表层和 $\mathrm{A} 5$ 站位 的底层海水 $\delta^{18} \mathrm{O}$ 相对偏负 $\left(\delta^{18} \mathrm{O}<0.10 \%\right)$, 而在 $\mathrm{A} 2 、 \mathrm{~A} 3$ 站位 $\delta^{18} \mathrm{O}$ 偏正 $\left(\delta^{18} \mathrm{O}>0.20 \%\right)$; 无其是在 $\mathrm{A} 9$ 站位的底层 $\delta^{18} \mathrm{O}$ 较偏正 $\left(\delta^{18} \mathrm{O}>0.40 \%\right.$ ) , 分别对应相对偏高的盐度, 盐度分布图可见在A8和A9站位底部存在次表层水的 爬坡现象.

$\mathrm{B}$ 断面海水 $\delta^{18} \mathrm{O}$ 变化范围为 $-0.04 \sim 0.58 \%$, 平均为 $0.30 \%$ (图5). 温度断面分布图显示B5、B6站位存在次 表层水(100 200m)的爬坡涌升现象(图5a), 在B5、B6 站位存在 $\delta^{18} \mathrm{O}$ 偏正核心 $\left(\delta^{18} \mathrm{O}>0.50 \%\right)$, 而盐度相对东 西两侧偏低 $0.1 . \mathrm{B} 7$ 站位 $\delta^{18} \mathrm{O}<0.20 \%$, 且在 $\mathrm{B} 8$ 以东的区 域可以明显观察到 $100 \sim 200 \mathrm{~m}$ 的次表层水体 $\delta^{18} \mathrm{O}>0.20 \%$, 而在 $300 \mathrm{~m}$ 水深以下海水 $\delta^{18} \mathrm{O}<0.20 \%$. 此 外, 与B5、B6站位水团性质相反, 在B2 B4站位盐度 相对较高 $(S>34.2)$, 而表层海水 $\delta^{18} \mathrm{O}$ 波动显著 (0.23 0.58\%).

$\mathrm{C}$ 断面海水 $\delta^{18} \mathrm{O}$ 变化范围为 $0 \sim 0.58 \%$, 平均为 $0.22 \%$ (图6). 断面自西向东表层海水 $\delta^{18} \mathrm{O}$ 先减小后增 大，在 $\mathrm{C} 2 \sim \mathrm{C} 6$ 站位之间水体 $\delta^{18} \mathrm{O}<0.20 \%$ ，最低值为 $0 \%$ ， 而在近岸 $\mathrm{C} 0$ 站位底层以及 $\mathrm{C} 1$ 站位的表层 $\delta^{18} \mathrm{O}>0.40 \%$. 同时, C6 站位以东 $100 \sim 200 \mathrm{~m}$ 左右的次表层水体 $\delta^{18} \mathrm{O}>0.20 \%$, 而大于 $300 \mathrm{~m}$ 深层水体 $\delta^{18} \mathrm{O}<0.20 \%$. 值得 注意的是, 与 $\mathrm{B}$ 断面类似, $\mathrm{C}$ 断面同样观察到在 $\mathrm{C} 5 、 \mathrm{C} 6$ 站位底部存在次表层水的爬坡涌升现象(图6a，6b). 对 比A、B和C断面, 均在水深100 200m处存在低温、高 盐 $(S>34.6)$ 以及 $\delta^{18} \mathrm{O}>0.50 \%$ 的水团, 这与前人的水文 观测结果一致( $\mathrm{Su}, 2004)$.

\subsection{HYCOM模式的流场及温度}

HYCOM模式输出的逐日海水温度和流场的分析 数据结果显示, 2018年4月10至4月 12 日, 台湾海峡西南 

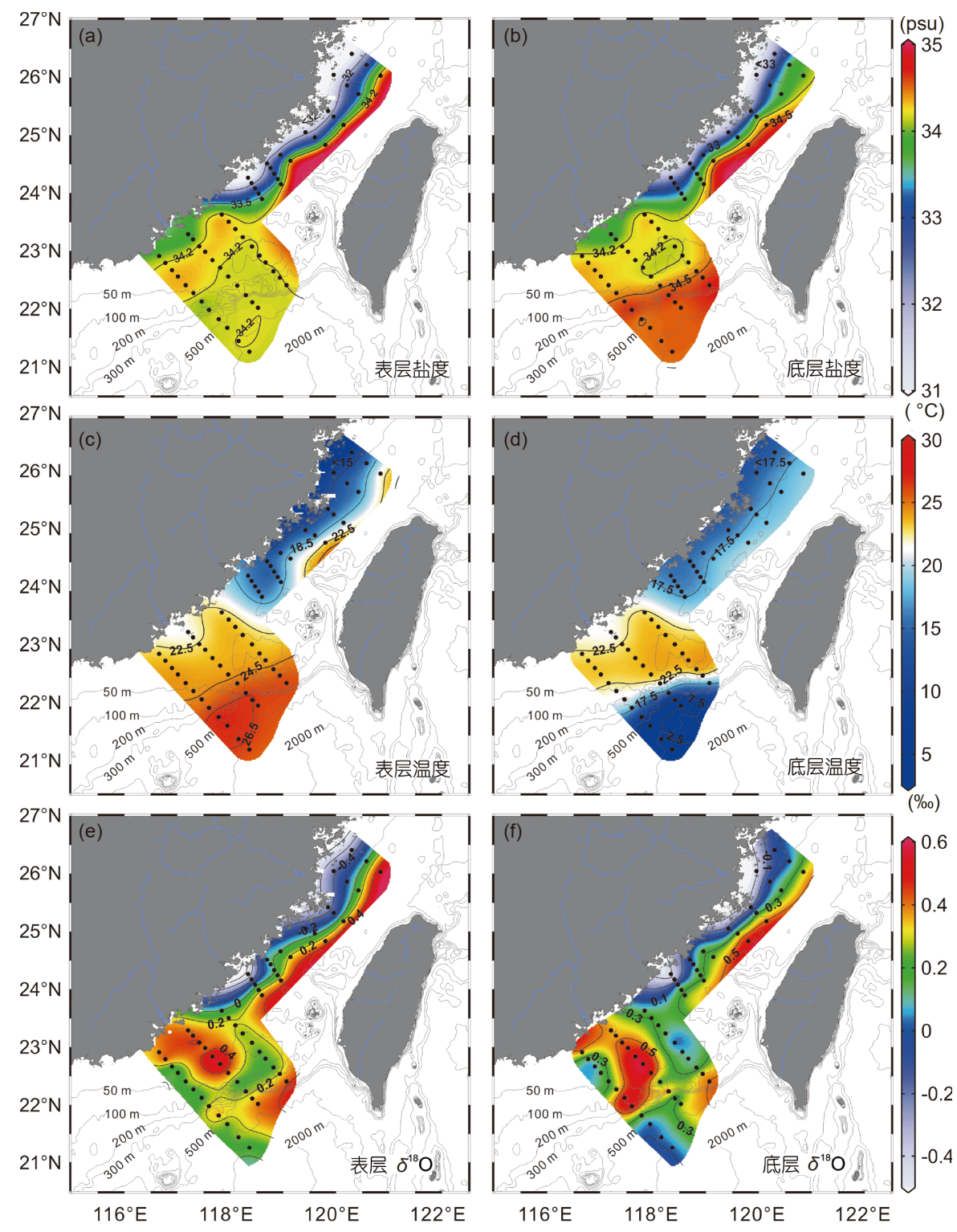

图 3 台湾海峡南部表层、底层海水盐度 $((a),(b)) 、$ 温度 $((\mathbf{c}) 、(d)) 、$ 氧同位素 $((\mathrm{e}) 、(\mathbf{f}))$ 水平分布图

部表层 $(0 \mathrm{~m})$ 和 $30 \mathrm{~m}$ 水深层存在一支温度较高 $\left(22.5 \sim 25^{\circ} \mathrm{C}\right)$ 的海流，从南海东北部沿着陆架区流向台 湾海峡内，表层和 $30 \mathrm{~m}$ 水深流速相当，为 $20 \sim 40 \mathrm{~cm} \mathrm{~s}^{-1}$, 该结果与样品采集期间现场观测到的高盐条带状水体 分布一致(图3 6)，指示南海暖流的延伸方向(图7). 台 湾南部即吕宋海峡附近可观察到一支向北流动的高流 速 $\left(>50 \mathrm{~cm} \mathrm{~s}^{-1}\right)$ 、高温 $\left(>24^{\circ} \mathrm{C}\right)$ 海流，沿着台湾岛东侧向 东北方向流动, 指示了黑潮入侵. 此外, 还存在一支显 著的高温海流入侵南海东北部海域, 并在大约 $118^{\circ} \mathrm{E}$ 位
置附近以反气旋的方式偏转入侵陆架，另外一部分继 续朝西南方向流动，这与前人报道的黑潮入侵南海方 式一致(Nan等，2015)。值得注意的是，在采样之前的 2018年4月6日至4月8日, 研究区经历强东北风天气(图 $2 b)$, 从4月7日到4月 12 日, 近岸的低温浙闽沿岸流范围 总体朝北逐渐变小，其中4月7日强东北风开始松弛阶 段，在 $118^{\circ} \mathrm{E} 、 24^{\circ} \mathrm{N}$ 处存在低温的近岸水体朝北折返 的现象，与观测及数值模拟结果一致(Shen等, 2017, 2019). 


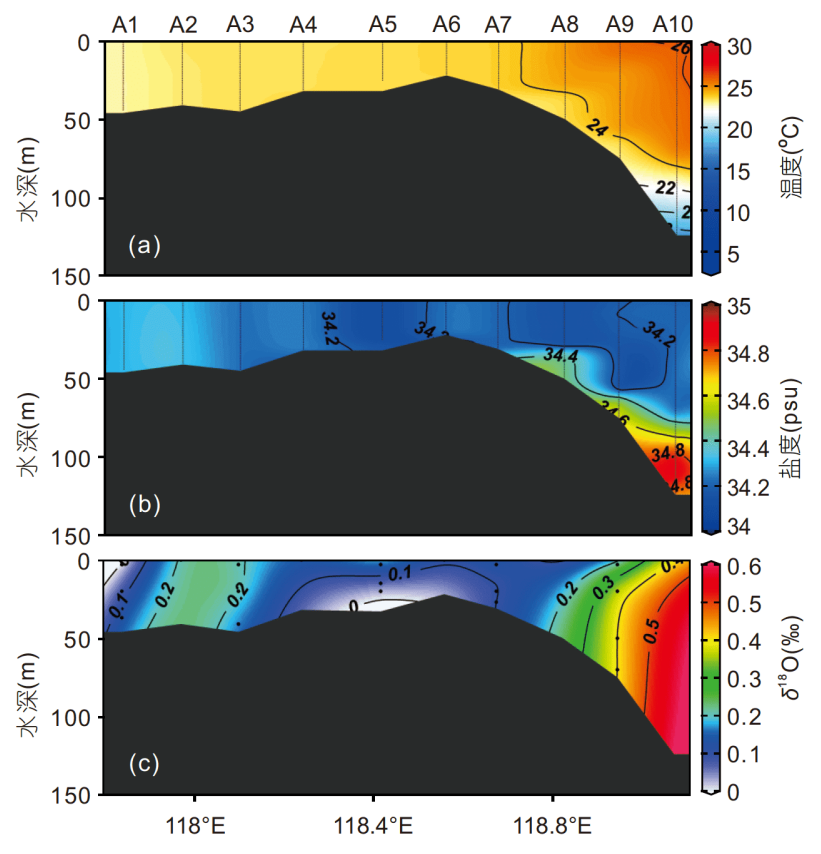

图 4 A断面海水温度(a)、盐度(b)、氧同位素(c)分布

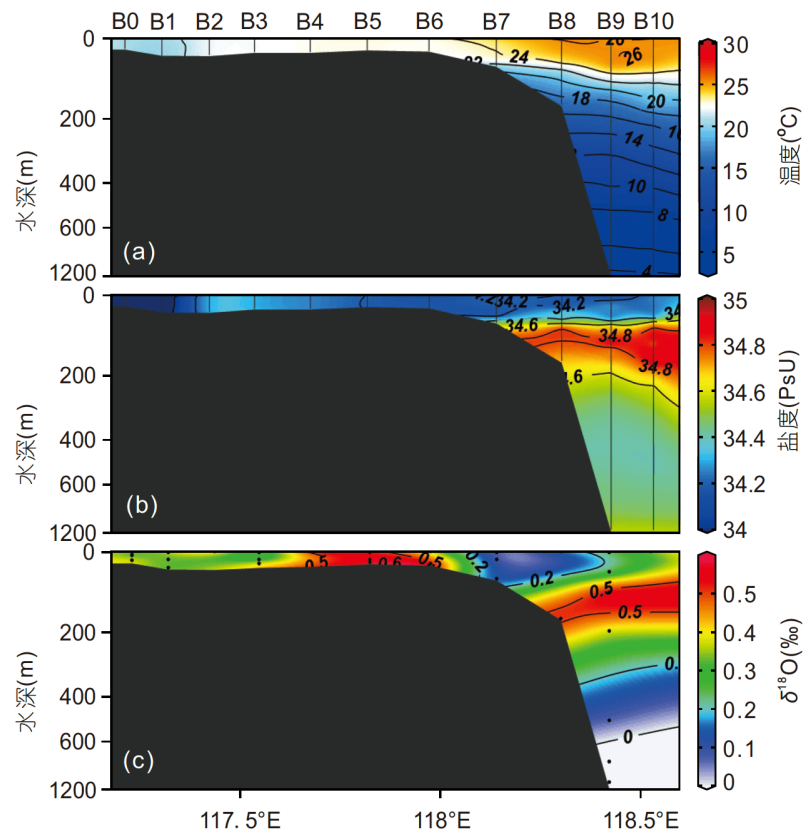

图 5 B断面温度(a)、盐度(b)、氧同位素(c)分布

\section{4 讨论}

\section{1 海水 $\delta^{18} \mathrm{O}$ 与盐度关系}

如图8 $\mathrm{a}$ 所示, 观测期间研究区海水 $\delta^{18} \mathrm{O}$ 与盐度存 在两种不同的线性关系，表明存在两个不同的水团混

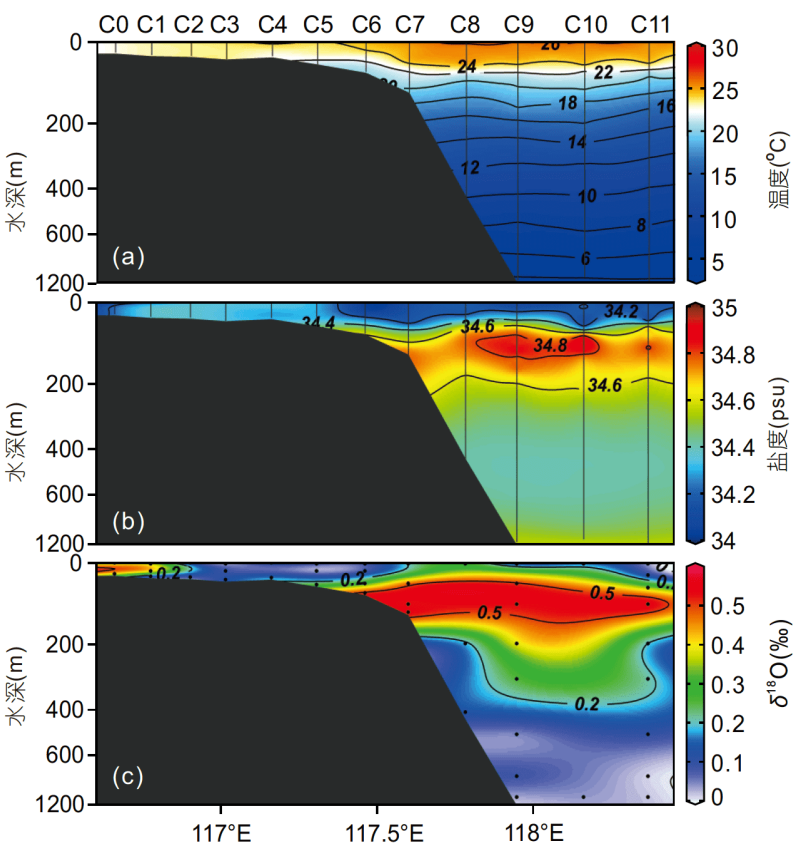

图 6 C断面海水温度(a)、盐度(b)、氧同位素(c)分布

合过程. 其中, 台湾海峡西北部浙闽沿岸流海水的 $\delta^{18} \mathrm{O}$ 与盐度关系为 $\delta^{18} \mathrm{O}=0.28 S-9.34, n=54, R^{2}=0.86$, 这与文 献报道的台湾海峡冬季 $(2000$ 年 3 月 $) \delta^{18} \mathrm{O}$ 与盐度关系 $\delta^{18} \mathrm{O}=0.28 S-9.38$ (Chang, 2000)基本一致. 依据海水 $\delta^{18} \mathrm{O}$ 与盐度的关系，当 $S=0$ 时，外推得出淡水端元的 $\delta^{18} \mathrm{O}$ 值为-9.34\%, 较中国东南部河流径流枯季的河水 $\delta^{18} \mathrm{O}(-7 \sim-6 \%$ ) 偏负(Yang等，2018; 王晨羽等，2018), 但与纬度相对较高的中国东部河流典型径流 $\delta^{18} \mathrm{O}$ 值 (-9.9 -7.1\%o)一致(Li等, 2016; Li等, 2015; Zhang等, 1990; 杜金秋等, 2012). 这表明观测期间受东北季风的 影响(图2b), 台湾海峡西侧海域受到北部浙闽沿岸流 的显著影响(Chang, 2000; Hu等, 2010).

结合 $\operatorname{Lin}(2000)$ 报道的1998年4月南海表层水体数 据, 台湾海峡西南部表层海水的 $\delta^{18} \mathrm{O}$ 与盐度关系为 $\delta^{18} \mathrm{O}=0.49 S-16.59, R^{2}=0.87$. 该结果与南海北部表层水 与黑潮水混合线基本一致: $\delta^{18} \mathrm{O}=(0.43 \pm 0.06) S-(14.58$ $\pm 2.06), R^{2}=0.85$ (Sue, 2000)和 $\delta^{18} \mathrm{O}=(0.47 \pm 0.07) S$ $-(15.81 \pm 2.40), R^{2}=0.62(\operatorname{Lin}, 2000)$; 且与西北太平洋表 层海水实际观测与模型得到的 $\delta^{18} \mathrm{O}-S$ 拟合线相当(LeGrande和Schmidt, 2011; Morimoto等, 2002), 表明台湾 海峡西南部表层海水显著受黑潮入侵影响，继承典型 西北太平洋表层海水的特征. 此外，南海北部表层水 与黑潮水的混合线相较于浙闽沿岸流具有更大的斜率 

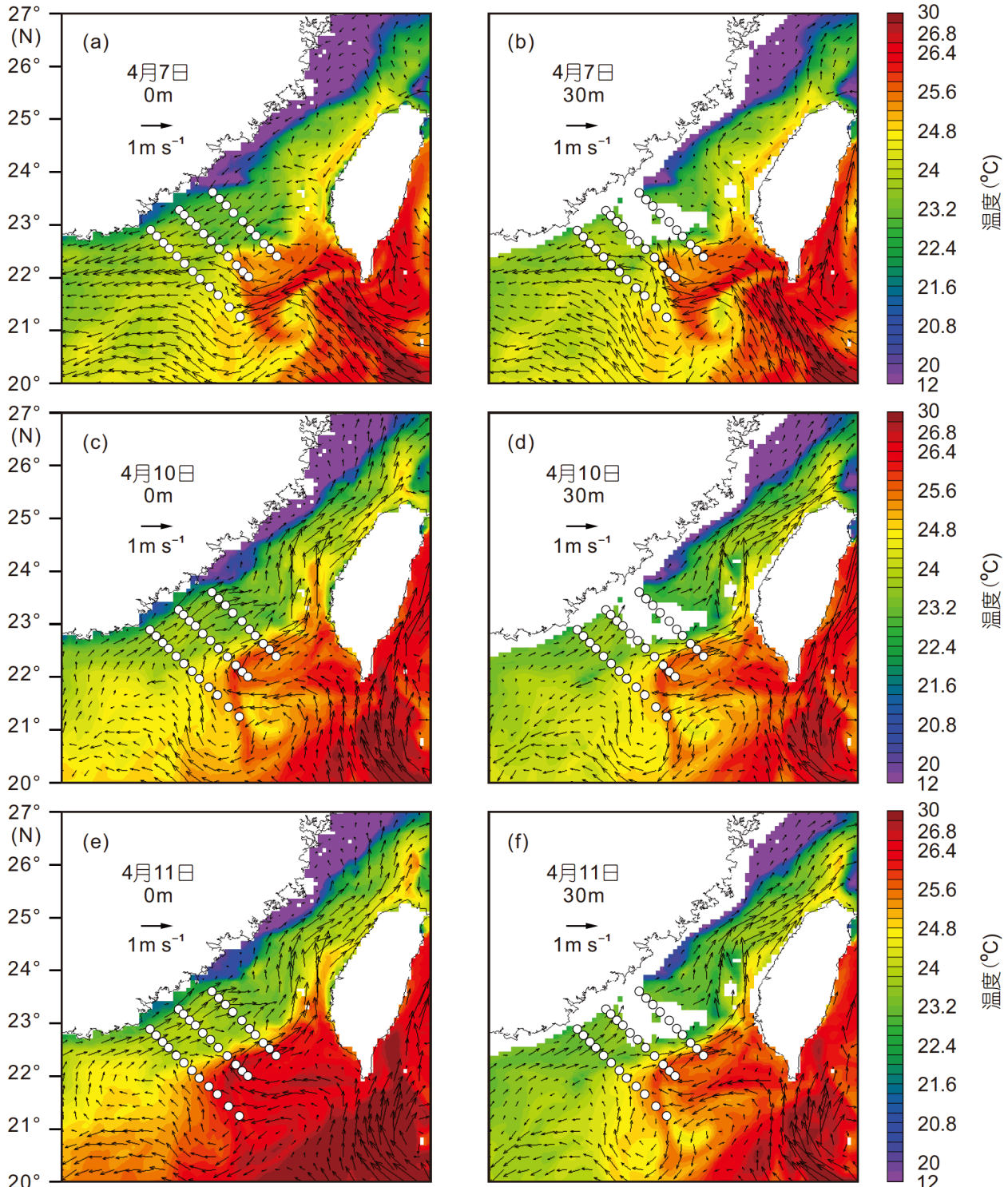

22.4

21.6

20.8

20

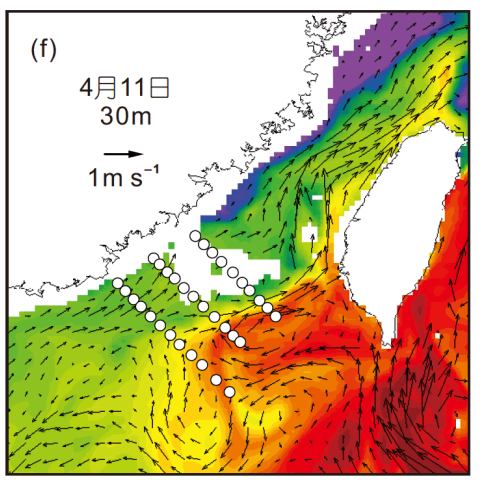

30
26.8
26.4

25.6

24.8
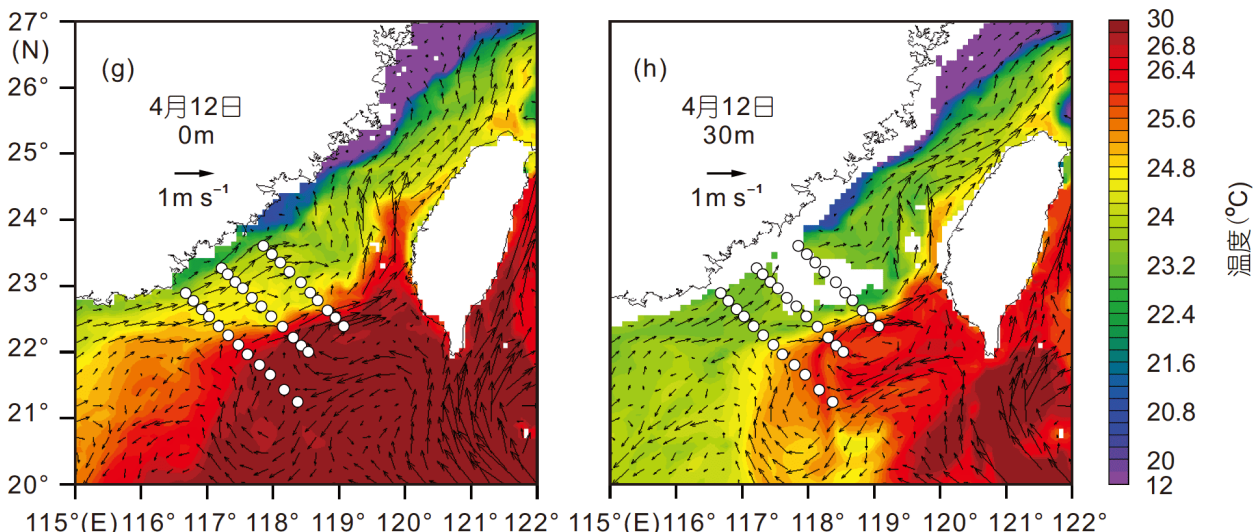

图 72018 年 4 月 7 日至 4 月 12 日台湾海峡 $0 \mathrm{~m} 、 30 \mathrm{~m}$ 水深流场及温度数值HYCOM模式图 数据来源: https://www.hycom.org/dataserver/gofs-3pt1/analysis, 白色圆点为ABC断面采样站位 
(0.49)和更小的截距 $(-16.59)$, 这是由于近岸海域受陆 地径流影响显著，而台湾西南部开阔海域的淡水主要 来源于大气降水, 且南海北部受热带气旋影响显著, 带来大量降水的同时，热带气旋较高的冷凝效率使其 具有异常偏轻的氧同位素组成 (Gedzelman和Lawrence, 1982; Lawrence等, 1998; Lawrence和Gedzelman, 1996).

\section{2 台湾海峡西南部不同水团识别及其氧同位素 特征}

依据本文和前人水文观测资料(Yang，2006; 管秉

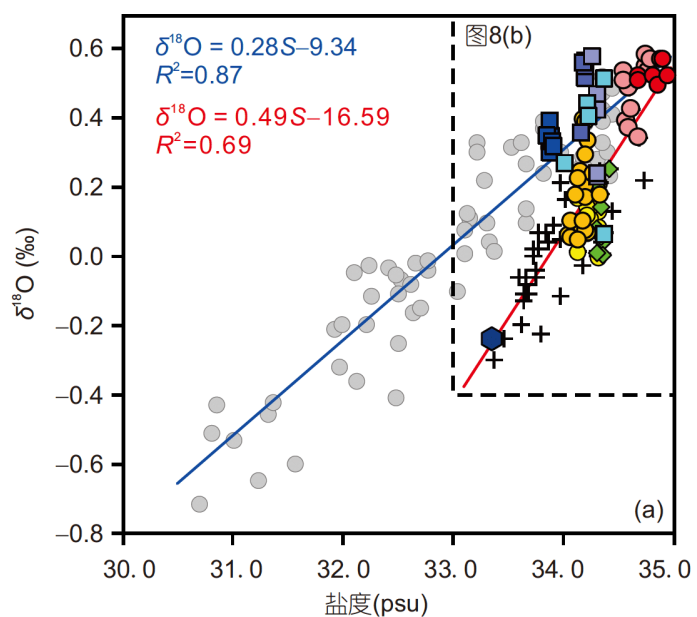

文献来源:

KSSW (Horibe和Ogura, 1964)

KSSW (150m, 2000/4, Chang, 2000)

$\operatorname{KSW}(2 \mathrm{~m}, 2000 / 4$, Chang, 2000)

吕宋海峡表层水(Lin, 2000)

南海东北部表层水( Lin, 2000)

典型南海表层水(0 50m, 2000/3, Chang, 2000)

典型南海表层水(Lin, 2000)

本研究:

$\begin{array}{llll}\square & \text { B0, B1 } & \bigcirc & \text { 陆坡流(5000m) } \\ \square & \text { B5, B6 } & \ominus & \text { C2 C5 (SCSWC) } \\ \square & \text { B2 B4 } & \bigcirc & \text { A1 A7(SCSWC) } \\ \square & \text { C0,C1 } & \bigcirc & \text { 台湾海峡浙闽沿岸流 }\end{array}$
贤, 1985; 孙湘平, 2006; 钟欢良, 1990), 观测期间台湾 海峡西南部可识别出的主要水团包括南海陆坡流、浙 闽沿岸流和南海暖流。

\subsection{1 南海陆坡流}

台湾海峡西南部水文观测及氧同位素结果显示在 A、B、C断面的 $100 \sim 200 \mathrm{~m}$ 的水深处存在一处低温 $\left(14.8 \sim 23.5^{\circ} \mathrm{C}\right)$ 、高盐(34.5 34.8) 和 $\delta^{18} \mathrm{O}$ 较正的水体, 并 向陆架方向爬坡至水深 50m处(图4 6), 系南海陆坡流 (孙湘平, 2006). 其 $\delta^{18} \mathrm{O}$ 值为 $0.34 \sim 0.58 \%$ o(图 $8 \mathrm{~b}$ ), 与典型 黑潮次表层水的 $\delta^{18} \mathrm{O}(0.49 \sim 0.57 \%$ ) 相符(Horibe和
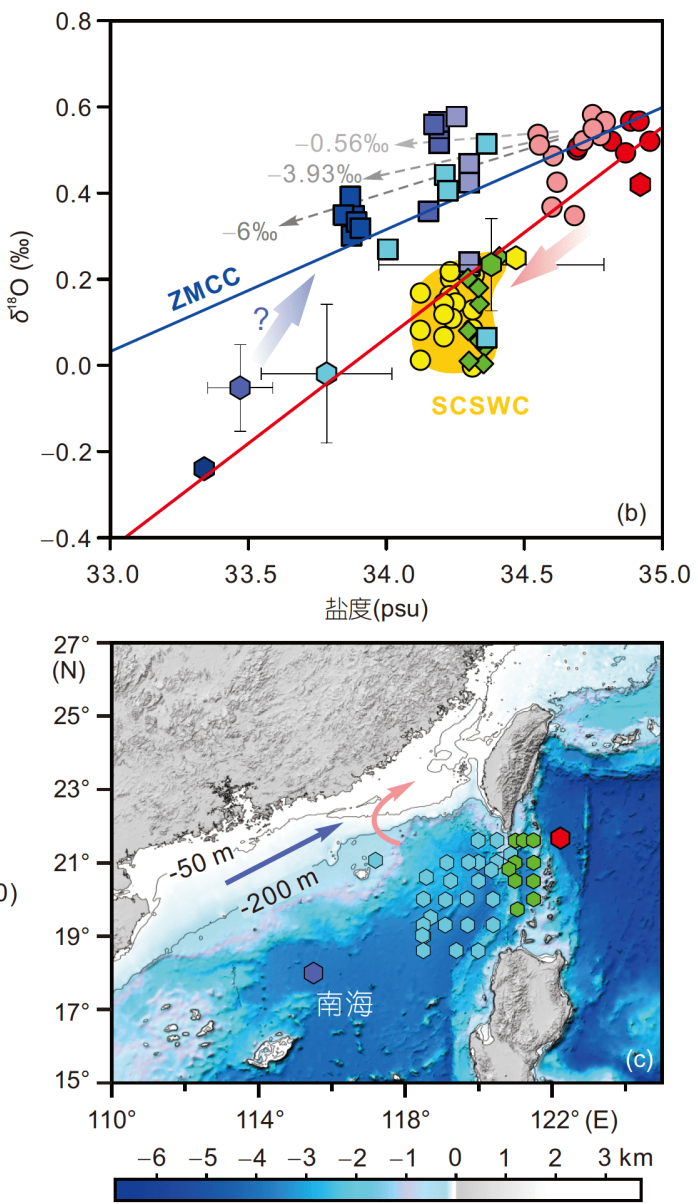

图 8 海水 $\delta^{18} \mathrm{O}$-盐度关系图(a)、海水 $\delta^{18} \mathrm{O}$ 与盐度关系局部放大图(b)和文献来源数据样品分布示意图(c)

(a) 黑潮次表层水(KSSW)和黑潮表层水(KSW)数据引用自Horibe和Ogura(1968)、Chang(2000), 典型南海表层水引用自Lin(2000)和Chang (2000). (b) $-6 \%$ 为冬季中国东南河流(珠江、九龙江及木兰溪)河水氧同位素平均值(L等, 2015; Yang等, 2018), $-3.93 \%$ 为福州大气降水 3 4 月多年加权平均值 (GNIP: Global network of isotope in precipitation, http://isohis.iaea.org), $-0.56 \%$ 为台湾屏东 $\left(120.69^{\circ} \mathrm{E}, 22.03^{\circ} \mathrm{N}\right)$ 的冬季多年大 气降水加权平均值(Peng等, 2010), 灰色虚线为两端元线性混合趋势, 红色箭头代表陆坡流对南海暖流的贡献, 蓝色箭头代表起源于海南岛东 部的南海暖流理论混合趋势. (c) 红色箭头代表黑潮入侵主控的陆坡流爬坡偏转形成的南海暖流, 蓝色箭头代表海南岛东部Ekman作用主控的 海表压力梯度驱动的南海暖流(Wang等, 2010; Wang等, 2011) 
Ogura, 1968; Kim等, 2005), 表明春季台湾海峡西南部 陆坡流主要来源于黑潮次表层水入侵, 这与前人的观 测和数值模拟结果一致(Hsueh和Zhong, 2004; Shaw和 Chao, 1994; Xue等, 2004).

\subsection{2 浙闽沿岸流}

如图 $8 \mathrm{~b}$ 所示，在台湾海峡西南部靠近韩江口的 $\mathrm{B} 0 、 \mathrm{~B} 1$ 站位，样品点主要落在浙闽沿岸流的 $\delta^{18} \mathrm{O}$ 与盐 度回归线上，在温盐点聚图上趋向浙闽沿岸流(图9a), 表明其主要来源于浙闽沿岸流的贡献，即春季浙闽沿 岸流末端可延伸至台湾浅滩(Liao等，2018). B2 B6、 C0 C1站位的样品主要落在浙闽沿岸流回归线上方, 且基本落在大气降水和当地河水输入端元 $(-6 \sim$ $-0.56 \%$ ) 与海水的混合范围之内, 表明这些站位除受 到浙闽沿岸流和当地径流(韩江、九龙江等)的影响以 外，还受到了区域大气降水的影响(Benetti等，2017; Benway和Mix, 2004).

\subsection{3 南海暖流}

本文水文观测资料及HYCOM模拟结果显示，观 测期间台湾海峡西南部陆架存在一条沿东北方向延伸 的高温高盐海流(图3、图7), 且温度断面分布图显示 等温线在该条带处朝西侧上倾(图4 6), 对应位势密度 $>23.0 \mathrm{~kg} \mathrm{~m}^{-3}$, 反映了其斜压地转流的特性, 与前人观 测的南海暖流温度结构特征一致(管秉贤, 1985, 1998; 郭忠信等, 1985). 历史水文资料表明, 南海暖流从海南 岛东部延伸至台湾海峡西南部, 呈现为一条相对高位 势密度条带 $\left(>23.0 \mathrm{~kg} \mathrm{~m}^{-3}\right.$ )(孙湘平, 2006), 且南海暖流 的盐度一般不超过34.5(郭忠信等，1985), 故本文将台 湾海峡西南部陆架区域位势密度 $>23.0 \mathrm{~kg} \mathrm{~m}^{-3}$, 盐度 $<34.5$ 作为南海暖流的识别标准(图9).

值得注意的是, B2 B6 和 $\mathrm{C} 1$ 站位样品温度、盐度 特征与南海暖流相似，而 $\delta^{18} \mathrm{O}$ 却表现出浙闽沿岸流的 信号(图8), 指示了浙闽沿岸流在台湾浅滩离岸偏转并 与外侧的南海暖流以等密度方式混合(图9). 然而, HY$\mathrm{COM}$ 分析资料输出的流场未见离岸输送的现象(图7), 这与观测期间的风向由东北风转为南风有关. 近来, Liao等(2018)发现冬季在台湾浅滩西侧约 $23.5^{\circ} \mathrm{N}$ 处存 在浙闽沿岸流向东南方向离岸偏转的现象, 这是受到 地形、风应力以及海表高度变化共同影响的结果( $\mathrm{Li}$ 等，2018). 海水 $\delta^{18} \mathrm{O}$ 对浙闽沿岸流在台湾浅滩处发生 偏转具有良好的指示作用(图8b)，较传统温盐点聚图 和HYCOM分析资料对水团的运动和起源判别更敏感.

因此, 剔除受浙闽沿岸流影响的样品, 台湾海峡西 南部南海暖流的代表性样品 ( $\mathrm{C} 2 \sim \mathrm{C} 5, \mathrm{~A} 1 \sim \mathrm{A} 7$ 站位) 的 $\delta^{18} \mathrm{O}$ 在0 0.25\% 0 (图8b). 考虑到典型南海表层水与黑潮 水的 $\delta^{18} \mathrm{O}$ 值在年际尺度上是相对稳定的(Lin, 2000), 同 时春季陆源输入的淡水以及沿岸流的 $\delta^{18} \mathrm{O}$ 值在季节时 间尺度内变化不大(Yang等, 2018), 且台湾海峡西南部 陆架区海水的滞留时间较短((14.3 \pm 10.3$)$ 天)(Liu等, 2012), 本文观测到的南海暖流已被充分更新. 并且, 南 海北部的沿岸流受冬季风显著影响, 沿岸线朝西南方 向流动(Hu等, 2000; Liu等, 2008), 受陆地径流影响显 著, $\delta^{18} \mathrm{O}$-盐度关系与浙闽沿岸流一致( $\mathrm{Ye}$ 等, 2014). 因 此, 可以将陆坡流、南海表层水、沿岸流的 $\delta^{18} \mathrm{O}$ 与南 海暖流进行对比, 并判别其来源.

\section{3 南海暖流起源}

$\delta^{18} \mathrm{O}$-盐度关系表明，研究区存在两种水团混合过 程, 即沿岸流与陆地径流的混合过程和南海表层水与 黑潮混合过程, 为南海暖流的起源判别提供了依据 (Benetti等, 2017; Lian等, 2016; Strauss等, 2012). 前人 水文观测及数值模拟结果表明南海暖流的潜在来源包 括南海陆坡流、南海表层水以及部分南海北部沿岸流 的贡献(Guan和Fang, 2006; Li等, 1993; Wang等, 2010; Wang等, 2011; Xue等, 2004; Zhang等, 2018; 钟欢良, 1990).

如图8b所示，台湾海峡西南部南海暖流样品点落 在了南海表层水与黑潮水的混合线上(图8b红色箭头), 而非南海表层水与浙闽沿岸流的混合线上(图 $8 \mathrm{~b}$ 蓝色 箭头); 且台湾海峡西南部南海暖流的 $\delta^{18} \mathrm{O}$ 平均为 $(0.15$ $\pm 0.13) \%$ ，较前人报道的南海北部表层水 $(0 \sim 50 \mathrm{~m}) \delta^{18} \mathrm{O}$ $((-0.05 \pm 0.1) \%$ \%)(Chang，2000)以及典型南海表层水的 $\delta^{18} \mathrm{O}(-0.24 \%)(\mathrm{Lin}, 2000)$ 均显著偏正. 这意味着台湾 海峡西南部的南海暖流在水体来源上不同于南海暖流 西段, 即本次观测到的南海暖流并非起源于海南岛东 部区域，南海暖流自海南岛东部向东北方向的延伸并 不连续.

早期水文调查认为, 南海暖流起源于海南岛东部, 并基本沿着 $100 \mathrm{~m}$ 等深线延伸至台湾海峡南部(管秉贤, 1978，1985), 为东北季风条件下海南岛地形阻挡导致 的水体在西边堆积, 形成的沿陆架方向海表高度差所 


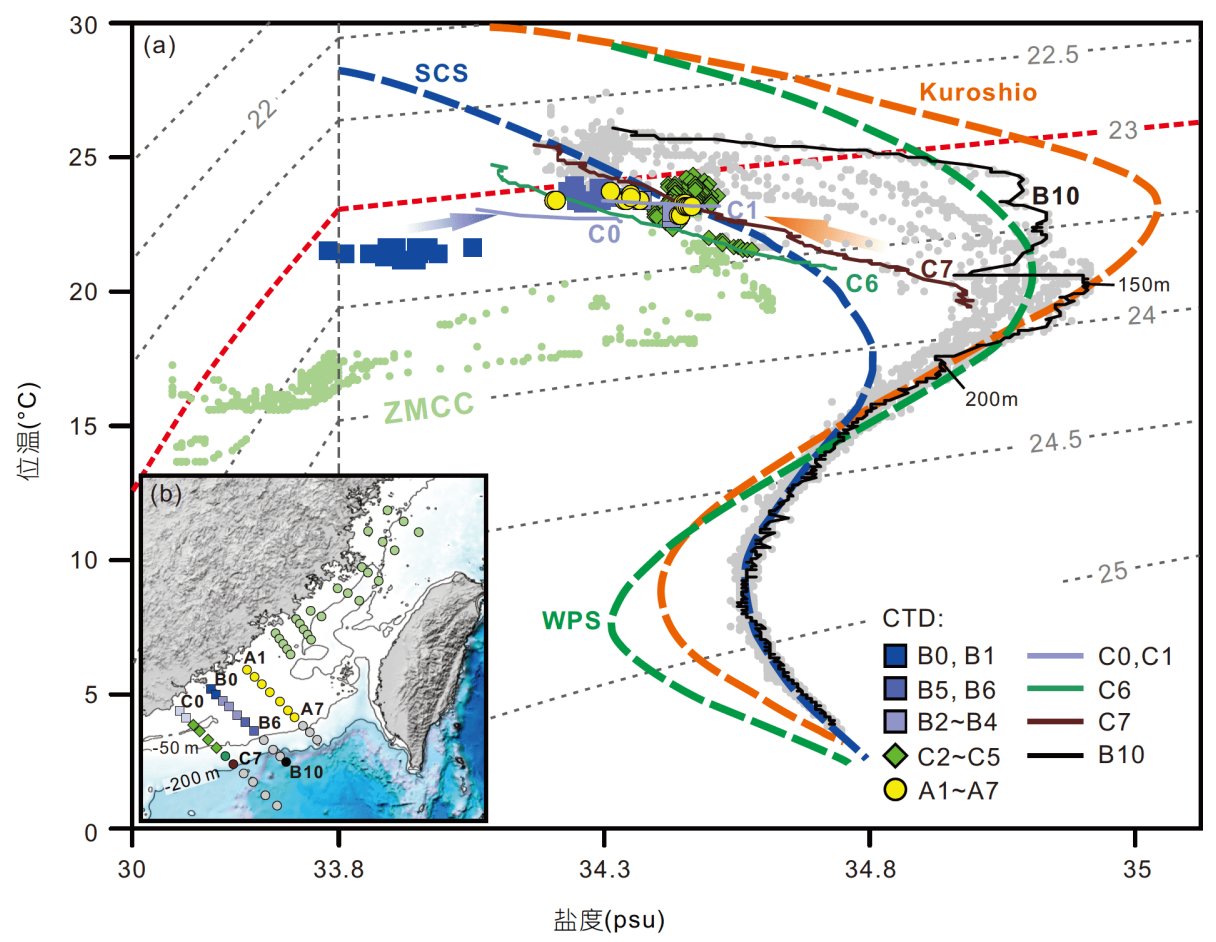

图 9 春季研究区温盐点聚图(a)和研究区站位分类分布图(b)

(a)中黑潮(Kuroshio, 橙色虚线)、南海海水 (SCS, 蓝色虚线)以及西菲律宾海海水(WPS, 绿色虚线)曲线引自Mensah等(2014). 蓝色箭头代表浙 闽沿岸流在台湾浅滩与南海暖流沿等密度面混合, 红色箭头代表陆坡流跨等密度面形成南海暖流

致(Li等, 1993; 曾庆存等, 1989); 另有观点认为沿陆架 方向海表高度差与热带西太平洋和西北太平洋之间的 海表高度差有关(Fang和Zhao, 1989). 然而, 近年来长 时间连续观测资料显示, 在南海北部珠江口外的陆架 区域并不存在连续的东北向海流( Li等, 2014; Tai等, 2017; Yang, 2006). 东北向的南海暖流仅出现在冬季 风松弛期间, 且东北向流主要位于表层 $50 \mathrm{~m}$ 以浅(Xie 等, 2015), 挑战了沿陆架方向的海表压力梯度成因机 制, 并支持了南海暖流主要受冬季风松弛影响的观点 (Chao等, 1995; Chiang等, 2008; Xie等, 2015). 尽管上 述两种观点尚存争议, 然而这两种成因机制的南海暖 流水体来源主要为海南岛东部堆积水体, 包含部分沿 岸流混入(Zhang等, 2018), 其 $\delta^{18} \mathrm{O}$ 理应相对偏负(即如 图 $8 \mathrm{~b}$ 蓝色箭头), 与我们的观测结果不符, 也解释不了 南海暖流西部流速弱, 东部流速强的特点(Guan和 Fang, 2006). 因此, 台湾海峡西南部南海暖流并非起 源于海南岛东部即南海暖流西段的延伸, 而是另有水 体来源与成因机制; 同位素证据也间接反映了南海北 部的南海暖流不是一支连续、稳定的海流(Guan和
Fang, 2006; Xie等, 2015; 管秉贤, 1985).

不同于上述沿陆架方向的海表压力梯度与冬季风 松驰成因机制, 黑潮入侵南海形成的黑潮南海分支(陆 坡流), 被认为是形成与维持南海暖流的主要成因. 根 据地形捕获波的理论, Hsueh和Zhong(2004)认为黑潮 入侵南海, 由于东沙地形的作用也会引起沿陆架方向 的压力梯度, 进而驱动南海暖流朝东北方向流动, 但 未给出其水体来源的解释. Xue等(2004)则认为黑潮入 侵产生的跨陆架密度梯度以及压强梯度力共同维持了 南海暖流的动力来源, 但台湾海峡西南部南海暖流水 体主要来源于黑潮入侵南海分支在南海东北部形成的 反气旋的北翼 (Nan等, 2015). 本文的HYCOM分析资 料也显示观测期间黑潮南海分支在吕宋海峡西侧有一 部分以反气旋方式偏转(图7), 入侵的黑潮表层水可能 形成了台湾海峡西南部的南海暖流. 然而, 台湾海峡西 南部南海暖流的 $\delta^{18} \mathrm{O}$ 较吕宋海峡西侧表层海水 $\delta^{18} \mathrm{O}$ 偏 正(图8b); 且位于南海暖流右侧的C6和C7站位的位温盐度曲线表明该处发生陆坡流次表层水的爬坡涌升 (图9a), 与水文断面观测结果相吻合(图6). 这表明观测 
期间台湾海峡西南部的南海暖流主要起源于黑潮入侵 南海形成陆坡流的次表层水，还受到表层水体跨陆架 方向混合的影响(Xue等，2004; 宏波和王东晓，2006). 近来，Wang等(2010)利用高分辨率模型提出了南海陆 坡流在JEBAR作用下次表层水向岸一侧爬坡偏转，构 成了南海暖流的动量和质量来源，而表层的跨陆架输 送则相对较弱, 佐证了我们关于南海暖流起源的推测. 当然，氧同位素数据并不能完全排除南海暖流西段的 贡献, 但这部分相对较少. 因此, 鉴于南海暖流在南海 东北部的生产力与环流结构中的重要性，为了进一步 厘清南海暖流的起源、动力机制及其在不同时空尺度 的变化规律，需要开展更长时间序列的现场观测与高 分辨率的数值模式研究.

\section{5 结论}

本文利用海水氧同位素指标，结合水文观测和 HYCOM分析资料，分析了春季台湾海峡西南部海水 $\delta^{18} \mathrm{O}$ 分布特征，结果表明研究区主要受黑潮入侵、南 海暖流、浙闽沿岸流的影响. 台湾海峡西侧浙闽沿岸 流的 $\delta^{18} \mathrm{O}$ 与盐度具有显著的相关性 $\left(\delta^{18} \mathrm{O}=0.28 S-9.34\right.$, $R^{2}=0.86$ ), 外推得到陆地径流的 $\delta^{18} \mathrm{O}$ 为 $-9.34 \%$, 较台湾 海峡西侧及西南部陆地径流 $\delta^{18} \mathrm{O}$ 值偏负，表明春季浙 闽沿岸流影响可至台湾浅滩处. 黑潮次表层水能够入 侵至台湾海峡西南部区域，其 $\delta^{18} \mathrm{O}$ 值介于 $0.34 \sim 0.58 \%$, 并在陆坡处伴有爬坡涌升的现象。观测期间台湾海峡 西南部南海暖流的 $\delta^{18} \mathrm{O}$ 为 $0 \sim 0.25 \%, \quad \delta^{18} \mathrm{O}$ 与盐度关系 进一步表明，春季台湾海峡西南部南海暖流起源于南 海北部陆坡流次表层水的爬坡偏转，而非来源于海南 岛东部形成的南海暖流西段，从水体来源和水团性质 的角度直接佐证了Wang等(2010)提出的JEBAR效应导 致陆坡流爬坡偏转形成南海暖流的观点. 同时，海水 $\delta^{18} \mathrm{O}$ 指示了浙闽沿岸流在台湾浅滩西侧约 $23.5^{\circ} \mathrm{N}$ 处离 岸输送，相比水文观测和HYCOM分析资料对水团起 源和运动的指示更敏感.

致谢该航次(航次编号: NORC2018-04)由“延平2号”科 考船实施，福建海洋研究所“延平 2 号”全体船员及科考人 员在样品采集中给予帮助, 厦门大学海洋与地球学院张 方涛工程师提供 CTD资料，两位若名评审专家提出宝贵 意见, 在此一并致谢.

\section{参考文献}

杜金秋, 陈敏, 曹建平, 邱雨生, 童金炉, 马嫱, 杨俊鸿. 2012. 南黄海 和东海海水 ${ }^{18} \mathrm{O}$ 的组成及其意义. 海洋与湖沼, 43: 1057-1066

管秉贤. 1978. 南海暖流—广东外海一支冬季逆风流动的海流. 海 洋与湖沼, 9: 117-127

管秉贤. 1985. 南海北部冬季逆风海流的一些时空分布特征. 海洋与 湖沼, 16: 429-438

管秉贤. 1998. 南海暖流研究回顾. 海洋与湖沼, 29: 322-329

管秉贤, 陈上及. 1964. 中国近海的海流系统. 青岛: 中科科学院海洋 研究所. 1-85

郭忠信, 杨天鸿, 仇德忠. 1985. 冬季南海暖流及其右侧的西南向海 流. 热带海洋学报, 4: 1-9

宏波, 王东晓. 2006. 南海北部冬季逆风流的动力诊断. 科学通报, 51: 9-14

舒业强, 王强, 组婷婷. 2018. 南海北部陆架陆坡流系研究进展. 中国 科学: 地球科学, 48: 276-287

孙湘平. 2006. 中国近海区域海洋. 北京: 海洋出版社. 201-285

王晨羽, 连尔刚, 杨承帆, 邓凯, 李超, 杨守业, 印萍. 2018. 浙闽中小 河流水体氢氧同位素组成特征及时空变化. 海洋地质与第四纪 地质, 38: 160-169

曾庆存, 李荣风, 季仲贞, 甘子钧, 柯佩辉. 1989. 南海月平均流的计 算. 大气科学, 13: 127-138

钟欢良. 1990. 密度环流结构. 北京: 海洋出版社. 215-241

Bauch D, Erlenkeuser H, Andersen N. 2005. Water mass processes on Arctic shelves as revealed from $\delta^{18} \mathrm{O}$ of $\mathrm{H}_{2} \mathrm{O}$. Glob Planet Change, 48: $165-174$

Benetti M, Reverdin G, Aloisi G, Sveinbjörnsdóttir Á. 2017. Stable isotopes in surface waters of the Atlantic Ocean: Indicators of ocean-atmosphere water fluxes and oceanic mixing processes. J Geophys Res-Oceans, 122: 4723-4742

Benway H M, Mix A C. 2004. Oxygen isotopes, upper-ocean salinity, and precipitation sources in the eastern tropical Pacific. Earth Planet Sci Lett, 224: 493-507

Chang C C. 2000. Spatial and temporal variation of ${ }^{18} \mathrm{O}$ in the sea water from the Taiwan Strait. Dissertation for Master's Degree. Kaohsiung: "National" Sun Yat-sen University

Chao S Y, Shaw P T, Wang J. 1995. Wind relaxation as possible cause of the South China Sea Warm Current. J Oceanogr, 51: 111-132

Chiang T L, Wu C R, Chao S Y. 2008. Physical and geographical origins of the South China Sea Warm Current. J Geophys Res, 113: $1-3$

Conroy J L, Cobb K M, Lynch-Stieglitz J, Polissar P J. 2014. Constraints on the salinity-oxygen isotope relationship in the central tropical Pacific Ocean. Mar Chem, 161: 26-33

Craig H, Gordon L. 1965. Deuterium and oxygen 18 variations in the 
ocean and the marine atmosphere. In: Tongiorgi E, ed. Stable Isotopes in Oceanographic Studies and Paleotemperatures. Pisa: Consiglio Nazionale Delle Ricerche Laboratorio Di Geologia Nucleare. $9-130$

Fairbanks R G. 1982. The origin of continental shelf and slope water in the New York Bight and Gulf of Maine: Evidence from $\mathrm{H}_{2}{ }^{18} \mathrm{O} / \mathrm{H}_{2}{ }^{16} \mathrm{O}$ ratio measurements. J Geophys Res, 87: 5796-5808

Fang G, Zhao B. 1989. A note on the main forcing of the northeastward flowing current off the Southeast China Coast. Prog Oceanogr, 21: 363-372

Ferronskii V I, Poliakov V A. 1982. Environmental Isotopes in the Hydrosphere. New York: John Wiley \& Son

Gedzelman S D, Lawrence J R. 1982. The isotopic composition of cyclonic precipitation. J Appl Meteorol, 21: 1385-1404

Guan B X, Fang G H. 2006. Winter counter-wind currents off the southeastern China coast: A review. J Oceanogr, 62: 1-24

Guan B X. 1986. Evidence for a counter-wind current in winter off the southeast coast of China. Chin J Ocean Limnol, 4: 319-332

Horibe Y, Ogura N. 1968. Deuterium content as a parameter of water mass in the ocean. J Geophys Res, 73: 1239-1249

Hsueh Y, Zhong L. 2004. A pressure-driven South China Sea Warm Current. J Geophys Res, 109: C09014

Hu J, Kawamura H, Hong H, Qi Y. 2000. A review on the currents in the South China Sea seasonal circulation South China Sea Warm Current and Kuroshio Intrusion. J Oceanogr, 56: 607-624

Hu J Y, Kawamura H, Li C Y, Hong H S, Jiang Y W. 2010. Review on current and seawater volume transport through the Taiwan Strait. J Oceanogr, 66: 591-610

Kim K R, Cho Y K, Kang D J, Ki J H. 2005. The origin of the Tsushima Current based on oxygen isotope measurement. Geophys Res Lett, 32: L03602

Lawrence J R, Gedzelman S D, Zhang X, Arnold R. 1998. Stable isotope ratios of rain and vapor in 1995 hurricanes. J Geophys Res, 103: 11381-11400

Lawrence R J, Gedzelman D S. 1996. Low stable isotope ratios of tropical cyclone rains. Geophys Res Lett, 23: 527-530

LeGrande A N, Schmidt G A. 2011. Water isotopologues as a quantitative paleosalinity proxy. Paleoceanography, 26: PA3225

Li C, Yang S, Lian E, Yang C, Deng K, Liu Z. 2016. Damming effect on the Changjiang (Yangtze River) river water cycle based on stable hydrogen and oxygen isotopic records. J Geochem Exploration, 165: 125-133

Li L, Guo X, Liao E, Jiang Y. 2018. Subtidal variability in the Taiwan Strait induced by combined forcing of winter monsoon and topography. Sci China Earth Sci, 61: 483-493

Li R, Chen C, Xia H, Beardsley R C, Shi M, Lai Z, Lin H, Feng Y, Liu
C, Xu Q, Ding Y, Zhang Y. 2014. Observed wintertime tidal and subtidal currents over the continental shelf in the northern South China Sea. J Geophys Res-Oceans, 119: 5289-5310

Li R, Zeng C, Gan Z, Wang W. 1993. Numerical simulation of the South China Sea Warm Current and the Taiwan Strait flow in winter. Prog Nat Sci, 3: 123-129

Li S L, Yue F J, Liu C Q, Ding H, Zhao Z Q, Li X. 2015. The O and H isotope characteristics of water from major rivers in China. Chin $\mathrm{J}$ Geochem, 34: 28-37

Lian E, Yang S, Wu H, Yang C, Li C, Liu J T. 2016. Kuroshio subsurface water feeds the wintertime Taiwan Warm Current on the inner East China Sea shelf. J Geophys Res-Oceans, 121: 4790-4803

Liao E, Oey L Y, Yan X H, Li L, Jiang Y. 2018. The deflection of the China Coastal Current over the Taiwan Bank in Winter. J Phys Oceanogr, 48: 1433-1450

Lin C F. 2000. Oxygen Isotope Compositions of Seawaters from the South China Sea and Luzon Strait. Dissertation for Master's Degree. Kaohsiung: "National" Sun Yat-sen University

Liu Q, Dai M, Chen W, Huh C A, Wang G, Li Q, Charette M A. 2012. How significant is submarine groundwater discharge and its associated dissolved inorganic carbon in a river-dominated shelf system? Biogeosciences, 9: 1777-1795

Liu Q, Kaneko A, Jilan S. 2008. Recent progress in studies of the South China Sea circulation. J Oceanogr, 64: 753-762

Ma H. 1987. On the winter circulation of the northern South China Sea and its relation to the large scale oceanic current. Chin J Ocean Limnol, 5: 9-21

Mensah V, Jan S, Chiou M D, Kuo T H, Lien R C. 2014. Evolution of the Kuroshio Tropical Water from the Luzon Strait to the east of Taiwan. Deep Sea Res Part I-Oceanogr Res Pap, 86: 68-81

Morimoto M, Abe O, Kayanne H, Kurita N, Matsumoto E, Yoshida N. 2002. Salinity records for the 1997-98 El Niño from Western Pacific corals. Geophys Res Lett, 29: 1-4

Nan F, Xue H, Yu F. 2015. Kuroshio intrusion into the South China Sea: A review. Prog Oceanogr, 137: 314-333

Peng T R, Wang C H, Huang C C, Fei L Y, Chen C T A, Hwong J L. 2010. Stable isotopic characteristic of Taiwan's precipitation: A case study of western Pacific monsoon region. Earth Planet Sci Lett, 289: 357-366

Shaw P T, Chao S Y. 1994. Surface circulation in the South China Sea. Deep Sea Res Part I-Oceanogr Res Pap, 41: 1663-1683

Shen J, Qiu Y, Guo X, Pan A, Zhou X. 2017. The spatio-temporal variation of wintertime subtidal currents in the western Taiwan Strait. Acta Oceanol Sin, 36: 4-13

Shen J, Zhang J, Qiu Y, Li L, Zhang S, Pan A, Huang J, Guo X, Jing C. 2019. Winter counter-wind current in western Taiwan Strait: 
Characteristics and mechanisms. Cont Shelf Res, 172: 1-11

Shu Y, Chen J, Li S, Wang Q, Yu J, Wang D. 2019. Field-observation for an anticyclonic mesoscale eddy consisted of twelve gliders and sixty-two expendable probes in the northern South China Sea during summer 2017. Sci China Earth Sci, 62: 451-458

Shu Y, Wang D, Feng M, Geng B, Chen J, Yao J, Xie Q, Liu Q Y. 2018. The contribution of local wind and ocean circulation to the interannual variability in coastal upwelling intensity in the Northern South China Sea. J Geophys Res-Oceans, 123: 6766-6778

Shu Y, Xiu P, Xue H, Yao J, Yu J. 2016. Glider-observed anticyclonic eddy in northern South China Sea. Aquat Ecosyst Health Manage, 19: $233-241$

Strauss J, Grossman E L, DiMarco S F. 2012. Stable isotope characterization of hypoxia-susceptible waters on the Louisiana shelf: Tracing freshwater discharge and benthic respiration. Cont Shelf Res, 47: 7-15

Su J. 2004. Overview of the South China Sea circulation and its influence on the coastal physical oceanography outside the Pearl River Estuary. Cont Shelf Res, 24: 1745-1760

Sue F H. 2000. Depth distributions of $\delta^{18} \mathrm{O}$ and Changes in mixed layer thickness in the South China Sea. Dissertation for Master's Degree. Kaohsiung: "National" Sun Yat-sen University

Tai J H, Yang K C, Gawarkiewicz G. 2017. Subtidal current structure and variability of the continental shelf and slope of the northern South China Sea. Terr Atmos Ocean Sci, 28: 411-423

Wallcraft A J, Metzger E J. 2009. Software design description for the HYbrid Coordinate Ocean Model (HYCOM). version 2.2

Wang D, Hong B, Gan J, Xu H. 2010. Numerical investigation on propulsion of the counter-wind current in the northern South China
Sea in winter. Deep Sea Res Part I-Oceanogr Res Pap, 57: 12061221

Wang Q, Wang Y, Bo H, Zhou W, Wang D. 2011. Different roles of Ekman pumping in the west and east segments of the South China Sea Warm Current. Acta Oceanol Sin, 30: 1-13

Xie J, Zhu J, Bertino L, Counillon F. 2015. Analysis of the northern South China Sea counter-wind current in winter using a data assimilation model. Ocean Dyn, 65: 523-538

Xue H, Chai F, Pettigrew N, Xu D, Shi M, Xu J. 2004. Kuroshio intrusion and the circulation in the South China Sea. J Geophys Res, 109: $\mathrm{C} 02017$

Yang J, Wu D, Lin X. 2008. On the dynamics of the South China Sea Warm Current. J Geophys Res, 113: C08003

Yang K C. 2006. The non-persistent South China Sea warm Current. Dissertation for Master's Degree. Taipei: "National" Taiwan University

Yang K, Han G, Liu M, Li X, Liu J, Zhang Q. 2018. Spatial and seasonal variation of $\mathrm{O}$ and $\mathrm{H}$ isotopes in the Jiulong River, Southeast China. Water, 10: 1677

Ye F, Deng W F, Xie L H, Wei G J, Jia G D. 2014. Surface water $\delta^{18} \mathrm{O}$ in the marginal China seas and its hydrological implications. Estuar Coast Shelf Sci, 147: 25-31

Zhang C, Ding Y, Bao X, Bi C, Li R, Zhang C, Shen B, Wan K. 2018. A numerical study of the South China Sea Warm Current during winter monsoon relaxation. J Ocean Limnol, 36: 216-229

Zhang J, Letolle R, Martin J M, Jusserand C, Mouchel J M. 1990. Stable oxygen isotope distribution in the Huanghe (Yellow River) and the Changjiang (Yangtze River) estuarine systems. Cont Shelf Res, 10: 369-384 